\title{
Human Systems Therapy: Use of Interpersonal Relations in Promoting Therapeutic Change
}

\author{
Nicholas C. Paritsis \\ Society for Human Systems Therapy and Intervention in Individuals, Families and Larger Systems, Athens, Greece \\ University of Crete, Crete, Greece
}

\begin{abstract}
The aim of this work is to present the central role of interpersonal relations in Human Systems Therapy (HST). Psychotherapies can be classified as (a) down-top therapies, such as individual therapies following reductionism, namely influencing the whole (behavior) through the intra-psychic parts, (b) top-down or holistic therapies, such as family therapies influencing the parts (individuals) through the whole family, and (c) the combination of down-top and top-down. Emotionally Focused Therapy (EFT) and Multisystemic Therapy (MST) act on two levels that influence each other, namely the individuals and their relations. This is also applied, more or less, on relational and interpersonal therapies. When there is an intervention in two interacting parts or levels, then the result of the intervention is more than additive and more effective. When the levels are more than two, then the effectiveness is expected to be even higher. This is the case of Human Systems Therapy (HST), which is applied intrapsychically, on interpersonal relations and on family and/or larger systems, with interpersonal relations having a central role. HST is based on general systems principles and it constitutes a multilevel approach: (a) a definition of a human system, (b) epistemology, (c) a model of human systems personality/intelligence, (d) an increase in order and variety. Besides, HST includes a large number of techniques. Empirical support of HST effectiveness shows that (a) after seven sessions with schizophrenics, $39 \%$ of psychotic symptoms are reduced, (b) after eight sessions with hashish adolescent users, all users stop the use completely, and (c) 9 out of 11 psychiatric non-psychotic cases (81\%), after four sessions, become non-psychiatric ones (treated).
\end{abstract}

Keywords: human relations, multilevel intervention, Human Systems Therapy

\section{Introduction}

There are a large number of psychotherapies that, according to the level of the living systems organization, can be classified as intra-psychic (individual), relational, couple, family, and so on. Furthermore, the general systems approach includes all the analytical (studying the parts and then understanding the whole), the holistic or synthetic approach (studying the whole and then understanding the parts), and the systemic one (studying (a) the parts and their relations and (b) the whole, and then understanding the parts and the whole). In that a system is the parts and their relations forming the whole and its emergent properties, and the whole in turn influences the parts, their relations, and their properties in a circular causation (see Checkland, 2012). The latter makes sense in family therapy.

Nicholas C. Paritsis, MD, Ph.D., Professor, Society for Human Systems Therapy and Intervention in Individuals, Families and Larger Systems, Athens; Department of Psychiatry and Behavioral Sciences, University of Crete, Crete, Greece. 
According to the level of intervention, there are different methods of (psycho) therapy. On the level of individual psychotherapy classic examples are psychoanalysis and cognitive behavioral therapy. They work and they intervene on an intra-psychic level. Interpersonal psychoanalysis (Sullivan, 1953) considers as very important human relations to be very important, which are also represented intra-psychically in a process called "personification" by Sullivan (1953).

On the level of methods of psychotherapy that influence human relations, examples are relational psychoanalysis (Greenberg \& Mitchell, 1983), and interpersonal psychotherapy by Gerald Klerman and Myrna Weissman (e.g., Klerman, Weissman, Rounsaville, \& Chevron, 1984), which are individual therapies that strongly consider the relationships. These are intra-psychic and thus they are down-top. Namely by influencing the lower level of the living systems organization (intra-psychic) they influence the higher ones (interpersonal).

On the level of family therapy examples are the Structural Family Therapy (Minuchin, 1974), and the Millan Family Therapy (Selvini Palazzoli, Boscolo, Ceccin, \& Prata, 1978). These approaches, by intervening in the family as a whole, change the parts and their properties. Family therapies are top-down approaches. Namely by influencing the higher level of living systems organization (family), they change the lower one, namely the parts (individuals).

There are two approaches that intervene in two consequent levels of human living systems organization. In this case the result is more than additive because the interaction between the levels results in a more than additive and closer to multiplicative effect, for mathematical reasons. These are Emotionally Focused Therapy (EFT) (Greenberg \& Johnson, 1988) and the Multisystemic Approach (Liddle, 2010).

Emotionally Focused Therapy (EFT) is mainly applied to couple therapy (Greenberg \& Johnson, 1988; 2013) although it can be possibly applied to cases of family therapy and individual therapy as well. Here, emotional responses based on past experiences determine relations that can be changed through interventions in emotions and on relations. Relations are viewed from a systems perspective. The intra-psychic processes mainly refer to attachment processes. The method of change is a top-down approach in that by changing relations emotions are changed, and also down-top approach in that by influencing emotions relations are changed. Emotions and behavior are changed in the context of relations. Because the intervention is on two levels, a multiplicative result is the outcome and it is highly effective.

Another case of intervention in two successive levels of living systems organization, namely the individual and the family one, is that of Multidimentional Family Therapy (MDFT) for adolescent drug abuse (Liddle, 2010). In this case the intervention is on the adolescent and their family. Here, once again, the results show that the method is highly effective.

It would be useful to integrate the individual, relational, couple, and family therapy in both top-down and down-top approaches.

There are General Systems Theory and Cybernetics that have principles equally applied to individuals, relationships, couples, families, and larger systems, as their principles can be equally applied from cells to individuals, to groups and nations (see Bertalanffy, 1971; Miller, 1978).

A General Systems Therapy that could be equally applied to individuals, couples, families, groups, and larger systems was developed in the past (Paritsis, 1989) and applied to the rehabilitation of schizophrenics (Paritis, 1989). Later on, this type of therapy further was developed further and its name was changed into Human Systems Therapy (HST) (Paritsis, 2010), after suggestions by Harline Anderson and Lynn Hoffman in 1998.

In the case of Human Systems Therapy, the core of the intervention is human relations, as the processes go 
from intra-psychic to relational, to family (and/or larger systems), and vice versa (Figure 1).

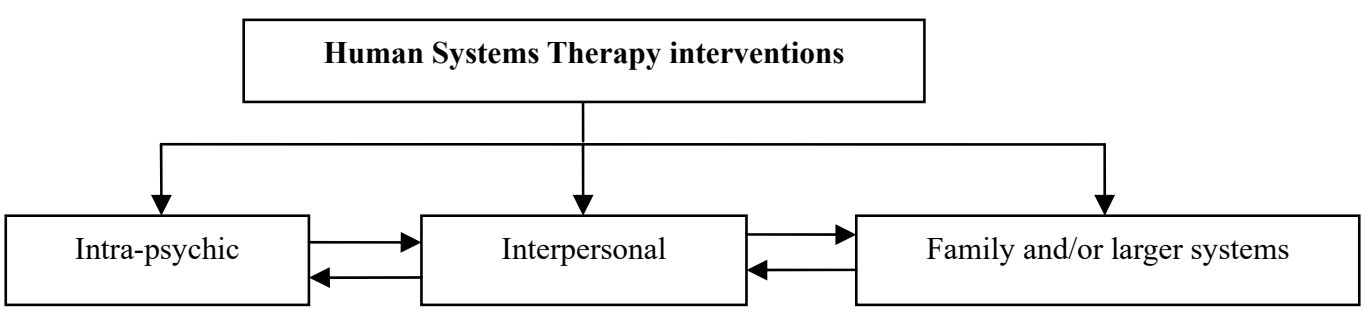

Figure 1. The interlevel relations in humanSystems Therapy.

\section{Human Systems Therapy}

\section{Introductory Remarks: HST and Multilevel Change}

According to HST, mental disorders, psychosomatic problems, and relational, couple, and family dysfunctions are related to the inability of persons to have intra-psychic strategies for interactions in order to achieve satisfaction and development - or to avoid dissatisfaction and harm-from particular human systems relations. In other words, in the above cases, the coping strategies for interpersonal relations are inadequate, dysfunctional, and problematic. These human maladaptive strategies influence relations within the family or other human groups. Besides, the inability of a person to have the above intra-psychic adaptive strategies for satisfactory interactions is circularly related to other parts and functions of the personality and in general other intra-psychic functions.

Furthermore, there are couple relations maladaptive and leading to problems and disorganizations and further maladaptive relations in the family (that may be related to an overall dysfunctional organization of the family) that trigger problematic behaviors or relations to their members (see Figure 2).

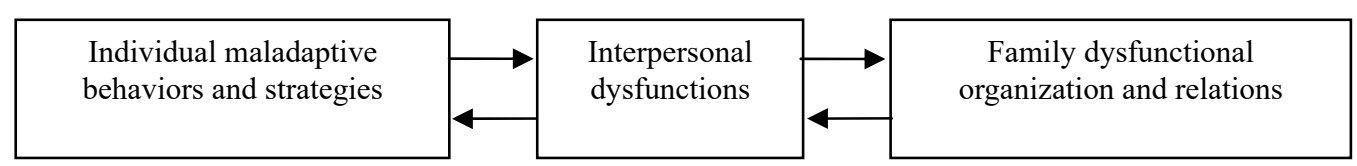

Figure 2. The relations of interlevel dysfuntions in top-down and down-top between the levels of living systems hierarchical organization.

In HST there are many down-top interventions, such as the intrapsychic intervention and in the structures where interpersonal relations are represented and modeled in order to influence relations and vice versa. These functional structures are called relational schemata in HST. Furthermore, there is an intervention in interpersonal relations (e.g., of the couple) in order to influence the function of specific individuals (e.g., a child). There are also interventions in the function of the family as a whole (e.g., schizophrenia). Also, with larger systems, such as schools, once again, the HST intervention is usually in a pair of persons (e.g., the parents, the student, and the teacher) or an individual (e.g., the director of the school, the teacher, the student).

At the same time there are top-down interventions, like (a) in the whole school in order to influence the relations of teachers and students, (b) in the whole family in order to influence schizophrenic symptoms, (c) in interpersonal relations in order to influence their intrapsychic strategies of behavior in couple violence. 
Furthermore, the dominant rules of functioning and the values of the wider society are also taken very importantly into account in the system under therapy.

The importance of interpersonal relations in HST, besides the above, is that the human systems motivation is toward interactions that lead to satisfaction and development (Paritsis \& Stewart, 1979; Paritsis \& Destounis, 1982). Since the interactions are through human relations within society, in order to get any form of satisfaction, human interactions constitute the core of interest and behavior according to HST.

\section{Theoretical Foundations of HST}

Multi-level definition of an open system including its relations with environment. An open system is a living system that interacts with its environment in order to maintain and develop itself through its interaction with its environment (Bertalanffy, 1950). Human systems are open systems. An open system constitutes the result of the interactions of its parts, of their relations, of the emergent properties of the system within its environment (Paritsis, 2006; 2010). This definition considers three levels, namely the parts and their interaction (first level), the emergent properties (second level), and the environment (third level).

Checkland (2012) also considers three levels: that of parts, that of the whole with emergent properties, and that of the environment. This definition has three levels and it concludes that when the system is an individual, then its parts have to be considered together with the system in which they are parts. If the system is a relationship, then the parts are the individuals. Then there are emergent properties of the relation (e.g., nice or conflicting), and the context can be the cultural context of the time and place they live or the wider social environment. As a result, HST is conceptualized on more than one level focusing on interpersonal relations. The intervention is spread on many levels having a multiplicative effect, and it is expected to be highly effective.

A multilevel epistemology of human systems. HST focuses on interpersonal relations and it is conceptualized on many levels. The related epistemology is also a multilevel unified process considering the biological, the social, and the scientific one.

Concerning the biological level, originally, Maturana (Maturana \& Varela, 1984), after his experiments on the color vision of the frog (Maturana, Lettvin, McCouloch, \& Pitts, 1960), suggested that reality is constructed in animals (Maturana, 1981) and, thus, in man. The reason was that the eye of the frog sees and encodes colors differently from its brain. However, later on, after experiments on macacus that sees colors similar to man, it has been found that the encoding of colors in its eye and its brain was the same. Thus, Maturana's constructionism lost its basic empirical facts. After that, it has been realized that man sees colors in a realistic way (for details see Paritsis \& Stewart, 1983). Thus, on the biological level all humans see reality in the same way in their brains.

Regarding the perception on the social level, Foucault $(1969 ; 2006)$ gave emphasis to the contribution of human relations to the dominant ideas and beliefs in social context, and Gergen (2009) gave emphasis to social relations in constructing social reality. Furthermore, persons usually consider propositions (issues) as true when they cannot be proved as false. In other words, if the negation of a proposition cannot be proved, persons may consider it as true, violating basic logical principles. In addition, emotions can further contribute modifying social reality.

On a scientific and technological level, reality is basically and generally understood and predicted due to scientific methods of today (see Popper, 1959). 
Reality is a very shaking concept. Senses have limitations and perceive a very small part of the universe. The term "reality" here is used in the sense of prediction and justification on the grounds of being useful in satisfying our needs.

In conclusion, although human senses and human science are contributing to a realistic perception of the world, social reality, social relations, and social and cultural issues are open to construction.

A model of human systems intelligence. Its basic structure as a living cybernetic agent. The overall structure of the model of human systems intelligence has the general structure of a purposeful system (see Rosenblueth, Wiener, \& Bigelow, 1943), namely of a controller (Winner, 1948). Its purpose is motivation towards interactions and relations that lead to satisfaction and development (Paritsis \& Stewart, 1979; Paritsis \& Destounis, 1982). Human systems can get their satisfaction through interactions and relations with other human systems. It follows that the central motivations of human systems are the relations with other human systems, by which they can achieve their satisfaction and development.

Furthermore, since any good controller must have a model of its environment (Ashby \& Conant, 1970), there is another part called model of the world, where also higher mental processes are realized.

Finally, since all living systems processing information have a part for exchanging information with the environment (Miller, 1978), there is a part for doing so (see Figure 3).

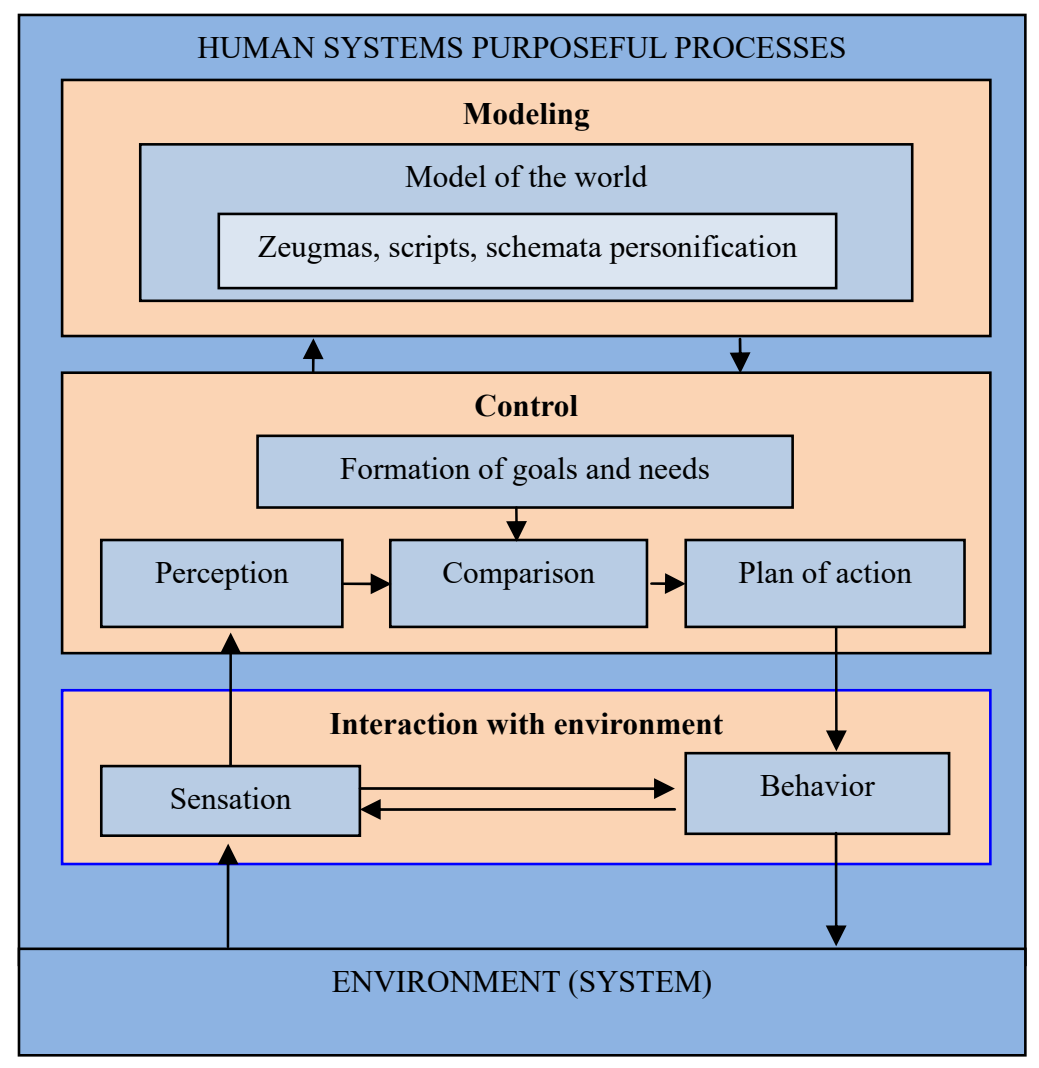

Figure 3. Definition of a system within its environment (Paritsis).

It is beyond the scope of this article to present details of this model, and this can be found elsewhere (Paritsis, 1985; 1987; 1999; 2006). 
General unconscious. There are three parts of the human systems intelligence that are of particular importance to HST. The first is the unconscious (Vedas, 2500 B.C., Paracelsus, 1494-1541) with paleologic thinking (Freud, 1898), which is accepted in HST as a general systems property present on all levels of human systems intelligence, such as the individual, the couple, the family, the group one, and so on. It is assumed that on all these levels there are unconscious parts functioning with paleologic thinking (Freud, 1899; Arieti, 1978). In this way, the unconscious with its paleologic thinking could be considered as a general (human) systems property. In fact, many most effective therapeutic techniques of HST could be explained through the palaeologic thinking of the unconscious of human systems.

Relational schemata. The second important part of the model of the world is that of realizing relations, namely the internal representation of the interactions, roles, and relations with other human systems named relational schemata or zeugmas. This is close to Sullivan's (1953) process of "personification". Intervention in human relations change relational schemata and intervention in relational schemata change interpersonal relations.

Motivation towards interactions. The third important characteristic of HST is that the basic purposes of human systems are interactions that lead to satisfaction and development. This is another reason for focusing on interpersonal relations. In our sociocultural system all of our needs are satisfied through social interactions. This is also why human relations are so important and any case needed psychotherapy of any form has to be related to human interactions and relations. The question is about the kind of the interactions that a person has the ability to fulfill in order to achieve development and satisfaction of their needs, and avoid harm. And also, what are the relations causes harm and dissatisfaction.

An increase in variety and order. Variety and order are two very important concepts in systems and cybernetics. Variety is the number of elements in a set. It is not the number of elements in a group. For example, a family may have four children: two boys and two girls. The number of children is four; the variety regarding the genter is two. Order is the opposite of entropy and is related to predictability. The more order, the more predictability.

In development, evolution, and therapy there is an increase in variety (Miller, 1978) and order (Prigogine \& Stengers, 1984) alone and much more in combination (Paritsis, 1993).

For this reason, the increase in variety and order in the case of therapy is used as a sub-goal and as an important strategy for change.

Variety. A direct implication of the law of requisite variety (Ashby, 1958) in cybernetics is that the more coping strategies a human system has, the more ability for adaptation and control it possesses. Thus, a very important strategy for therapy is to enrich the human system with adaptive strategies and reduce the maladaptive ones. These strategies are embodied also in relational schemata. The change of the maladaptive strategies into adaptive ones can take place through direct influence in the individual and their interpersonal relations and family. The way of doing so is through various techniques of HST and of other schools of therapy. The maladaptive interactions are usually replaced with adaptive ones, while new adaptive strategies are formed through the therapy. In this way there is an increase in the variety of adaptive strategies, interactions, and relations in therapy.

Order. Increase of order in therapy includes the form of increasing collaborative, positive, and loving relations, reduction of internal (within the system) conflicts, communication towards agreement, hierarchy according to dominant cultural principles, balance between give and take, interactions leading to satisfaction 
and development.

Besides, there is logical order, namely the logical coherence in the human systems, lack of discrepancies, agreement in principles and values, and reduction of ambiguity.

Order must also be present between the official and the actual rules. Actual rules are the rules and principles that a system uses in practice, and official are the rules and principles of the supra or meta-system. Thus, in order for a society to have order, it has to make sure that its rules and principles are followed by its families as well as its members. Another way to increase order is by adding rules. This is so for all levels of human systems organization.

\section{Techniques and Methods of Change}

Structure and steps of conducting HST. The first step is the establishment of good and trusting interpersonal relations with the client(s). The second step is to submit the inquiry to the client(s) about the reasons of their visit in detail. These two steps may last for the whole first and/or the second meeting.

The third step is to make hypotheses, mainly and usually concerning the relational and interpersonal dysfunction(s) of the client. There are already available hypotheses for most cases (e.g., psychiatric, psychosomatic, couple difficulties, family violence and abuse, school problems). These hypotheses may come from the literature, independent of the schools of therapy, from research or from observations (for more than 50 years), from colleagues or students, which were tested continuously in therapy in the institutions where the author worked.

The fourth step is to test the hypotheses by submitting further inquiries or by interventions.

The fifth step is the use of techniques for change.

No steps other than the previous five ones are used. Advice, explanations, practical solutions and suggestions are considered to be damaging and/or loss of time, and are strictly avoided. If necessary, the therapist of HST can go back to any of the previous stages from one to fifth till the end of therapy, and the steps are in a circular manner.

Techniques. There are over 30 techniques developed in the context of HST. We are going to present four of them as examples of demonstrating a way of thinking. One of them, "overpositive description", is suitable for all cases and usually for neuroses, another technique, "refutable logical consequences", for psychoses, one other, "ignorance of consequences", for depression, and "therapeutic alchemy" for all cases.

Over-positive description. The therapist is concentrated and whenever possible presents any possibly positive characteristic of the client over-positively, to the extent that they can support it with arguments. For example, a nice lady is described as beautiful, a scientist as a very clever person. This technique is always helpful for the reduction of anxiety, for the increase in self-confidence, and so on. It is different from emphasizing the positive of Henggeler (1999).

Refutable logical consequences. The therapist accepts any delusion and hallucination as real and valid, and then tries to find a logical and compatible with the hallucination or delusion consequence which is undesirable for the client. For example, in the case of a man who believes that he has a machine in his brain, the therapist finds the solution of performing an operation in the next few days. During the next session the schizophrenic says that the machine has disappeared.

Ignorance of consequences. The therapist asks the client (when there is depression or depression-related cases) which the client's biggest mistake has been. Then if the client describes a situation where the clients' 
behavior was based on a wrong estimation or ignorance of the consequences, then the therapist asks "If you had known the results, would you have done it?" When the client says "no", then the therapist says "You are not guilty, and your intentions were pure".

Therapeutic alchemy. When the client has a will, an action, an emotion, or a belief that is related to aggression (and in general is considered bad), then the therapist finds a positive and nice part in it (a member of the set) and presents it as something nice. Then the client usually abandons this symptom, behavior, or belief. Therapeutic alchemy has a small overlap with positive connotation of the Milano School, but without being the same. Positive connotation concerns something about the whole family, in respect of good will or positive practical consequences. Therapeutic alchemy has a much wider applicability, to individuals and their personal relations and to any system. Plus, it is not restricted to good will and positive consequences. It is much wider, based on different conceptualization.

For example, a schizophrenic client is very angry and very aggressive with all the citizens of his village because of the somatic hallucinations that the minister of Navy has sex with him. The therapist congratulates the schizophrenic of the fact that the Minister of Navy has chosen him, and tells him that he should be proud. The client almost immediately responds by saying he probably is wrong and this is not true and then calms down. Here the issue does not concern the whole family; it has nothing to do with good will from the client and it does not have any positive practical consequences.

\section{Empirical Support and Evaluation}

The empirical support and evaluation of HST refers to the reduction of the problem (or the improvement of it concerning the goals of therapy), in relation the time spent and the effort made, namely how much improvement in how much time.

One control trial was carried out on schizophrenic patients and their families (individual and family therapy) for reduction of their psychopathology in order to help them find a job. The intervention was individually in the schizophrenics or their families. After seven sessions, the reduction of their psychotic psychopathology was statistically significant (delusions and hallucinations were at 39\%). We had influenced and reduced the critical comments of the parents towards their schizophrenic children, promoting good relations between parents, and applying paradoxical techniques on relations and delusions and hallucinations of the individuals (see Techniques). According to our knowledge, there is no other psychotherapeutic method that after seven sessions succeeded in reducing psychotic symptoms to $39 \%$.

Another control trial (Lambraki, Kilaidakis, \& Paritsis, 2014) was carried out on adolescent hashish users. After eight group therapy sessions all users stop using hashish at all. The only thing we did was to promote better and more relations of the users with their family and their friends, including the improvement of the users' ability and desire to have satisfactory human relations. According to our knowledge, there is no other psychotherapeutic method that after eight sessions succeeded in making adolescent hashish users stop using hashish at all.

In a recent trial (Lambraki \& Paritsis, 2019) the connection between individual psychopathology via General Health Questionnaire and family functioning via SCORE (Stratton et al., 2014) was measured. The intervention was in individuals or their families. A statistically significant relation was found between the two. In the same trial, $81 \%$ of cases were classified as psychiatric ones, according to their symptoms, but after four sessions, they stopped being psychiatric cases, according the criteria of GHQ. These are the best results in 
bibliography concerning the degree of improvement, in terms of the number of sessions or time spent.

\section{Discussion}

\section{Foundations of HST}

HST is purely based on systemic cybernetic principles. Besides that, there is also the process of the unconscious with its paleologic thinking from the Freudian Interpretation of Dreams (Freud, 1899). This unconscious with its paleologic thinking is considered by HST to be present on all levels of human systems intelligence, and, hence, it is becoming by definition a General Human Systems Intelligence characteristic, applied to individuals, couples, families, and larger systems. The presence of intelligence in larger than humans is well accepted by Miller (1978), Beer (1972), Maturana, talking about the unconscious consensus (in the 1980s), by the Milano School (Selvini Palazzoli et al., 1978), talking about the beliefs of the family, by Hellinger (2003), talking about the soul of the family. Our position is that in all human systems intelligence where information is processed, there is also an unconscious part besides the conscious one.

Furthermore, a process described in cognitive psychology as scripts, in human cognition as schemata, in artificial intelligence also as schema, and in systemic psychology as cognitive/emotional structures (Gray, 1973), and in HST it is called relational schemas (as a more general idea). Schemata are already used in artificial intelligence, and cybernetics.

The multilevel definition of a system is also based on Checkland's (2012) views, including environment, to a certain degree, the work of Ashby about the model of the world in the controller.

Thus, all basic concepts and processes in HST come from General Systems and Cybernetics, apart from the unconscious paleologic thinking, which comes from Freud and is used as a general systems property for all levels of human systems intelligence, and, thus, it has become and considered a systemic one in this sense too.

\section{The Advantage of a Multilevel Systemic Approach With Concentration on Interpersonal Relations}

The role of human relations is of considerable interest in all aspects and types of psychotherapy. In psychoanalysis there are the relations of the child with their parents and the internalization of these relations. Also, in psychoanalysis and psychoanalytic psychotherapy, there is the process of transference. In the cognitive behavioral tradition schemata are present, realizing interactions. In couple therapy and family therapy the relations of the participants in therapy are present. In Sullivan's theory and relational therapies relations are even more involved.

In HST human relations are under consideration and present in one way or another, including intra-psychic representations, in human relational therapy and in family and larger systems therapy, with a multilevel multiplicative effect. Considering the time spent according to the mentioned above research trials and the everyday application of HST, for an average therapy for usual issues (non-psychotic), one needs to estimate 5-7 sessions within 2-3 months. This is, however, not based on meta-analysis or on effect sizes. Thus, it is an indication based on empirical facts that are probable but not proved.

\section{The Advantage and Compatibility of Motivation Towards Interactions With Intervention in Human Relations}

In human society within the present western civilization all our needs are basically covered via human systems interactions and relations, from food and sex to relief from pressure and the use of technology and art. Thus, human interactions are the core and necessity for satisfaction. Hence, human relations are the only means 
for achieving satisfaction. The acceptance that people's motivation towards interactions through human systems achieves satisfaction of their needs leads us to investigate and concentrate on human relations and search the causes of problems.

\section{The Role of Relations}

In practice, most of the interventions are in human relations. Also, the (main) reasons why somebody attempts to practice therapy are usually centered around particular relations. Furthermore, the therapist of HST employs particular techniques among the above-mentioned 30 ones, or from other schools of psychotherapy, most of which are compatible with the theory and epistemology of HST. Sometimes the relations in question may be in the past; other times the relations are in the context of the family, or of a couple (in the present). Sometimes particular relations lead to other disturbing relations. Sometimes families have general rules that influence a number of relations.

\section{Effectiveness of HST}

The results of the above-mentioned research trials - (a) in the case of schizophrenia, 39\% of the psychotic symptoms had been reduced after eight sessions, (b) in the case of hashish users, the participants had stopped using hashish after eight sessions, (c) and in the case of psychiatric non-psychotic cases, $81 \%$ of these cases had ceased being psychiatric ones after four sessions - are the best so far in the literature. Also, our students, after their training, manage to cover the needs of the clients in less than 10 sessions on the basis of videos and individual and family questionnaires. These results are not based on the personal beliefs and feelings of the clients or the therapist, but on objective measures and statistics. All the above make HST be briefer than Palo Alto's brief therapy, DeShazer's therapy, and any type of cognitive therapy or relational therapy.

The reason for these advantages may be due to the multilevel intervention focusing on interpersonal relations independent of the level of intervention. A second factor of success may be the strategy and techniques used as applied also to individuals and to interpersonal relations. A third factor may be hypothesizing and testing the hypothesis. A fourth factor can the numerous and very effective techniques of HST. A fifth factor is considered the ready hypotheses (tested in the course of more than 30 years) for each of the categories of cases coming for treatment. The ability of HST to cover the needs of the clients and the treatment of cases effectively in less than 10 (usually 6-7) sessions can be also demonstrated through available videos and questionnaires concerning the final test of our four-year training program in Systemic Therapy.

\section{Conclusions}

The multilevel intervention that always considers human relations,

- the core etiology of particular categories of cases that is about relations,

- the motivation towards relations,

- the overall structure of epistemology with difficulties on perceiving relations (partially constructed),

- the overall structure of mental processes for interactions with the environment and,

- the increase in order and variety concerning relations with the environment,

is making HST the most "relational" therapy, which at the same time appears to be the most efficient and fast one, so far.

\section{References}

Aivalioti, E., Trikas, P., Chrisos, P., Papageorgiou, P., Katahanakis, K., \& Paritsis, N. (2009). Reduction of psychotic symptoms 
in people with schizophrenia, using Human Systems Therapy, a randomized controlled trial. Human Systems: The Journal of Therapy, Consultation \& Training, 20(1), 81-98.

Alexander, F. (1950). Psychosomatic medicine. New York: Norton \& Company.

Arieti, S. (1978). On schizophrenia, phobias, depression, psychotherapy and further shores of psychiatry. Selected papers of Silvano Ariety. New York: Brunner/Mazel.

Ashby, R. (1958). An introduction to Cybernetics, Chapman and Hall. London.

Ashby, R., \& Conant, R. (1970). Every good regulator of a system must be a model of that system. Int. J. Systems Sci., 1(2), 89-97.

Beer, S. (1972). The brain of the firm. Hardmondsworth: Allen Lane, Penguin.

Berger, P. L., \& Luckmann, T. (1966). The social construction of reality: A treatise in the sociology of knowledge. Garden City, NY: Anchor Books.

Bertalanffy, L. (1950). The theory of open systems in physics and biology. Science, 111(2872), 23-29.

Bertalanffy, L. (1971). General systems theory. London: Penguin Press.

Checkland, P. (2012). Four conditions for serious systems thinking and action. Syst. Res., 29, 465-469.

Foucault, M. (1969). The archaeology of knowledge. (A. M. Sheridan Smith, Trans.). London and New York: Routledge.

Foucault, M. (2006). The history of madness. New York: Routledge.

Freud, S. (1898, released 1900). The interpretation of dreams. 1910 The interpretation of dreams the illustrated edition 2010. Sterling Press, pages 9-68.

Gergen, K. (2009). Relational being: Beyond self and community. Oxford: Oxford University Press.

Gray, W. (1973). Emotional-cognitive structures. A general systems theory of personality. General Systems, 18, 167-173.

Greenberg, J. R., \& Mitchell. S. A. (1983). Objects relations in psychoanalytic theory. Cambridge: Havard University Press.

Greenberg, L. S., \& Johnson, S. M. (1988). Emotionally focused therapy for couples. New York: Guilford Press.

Greenman, P. S., \& Johnson, S. M. (2013). Process research on Emotionally Focused Therapy (EFT) for couples: Linking theory to practice. Family Process, 52, 46-61. doi:10.1111/famp.12015

Henggeler, S. (1999). Multisystemic therapy: An overview of clinical procedures, outcomes, and policy implications. Child Psychology \& Psychiatry Review, 4(1), 2-10.

Hellinger, B. (2003). Peace begins in the soul: Family constellations in the service of reconciliation. (C. Beaumont, Trans.). Heidelberg, Germany: Carl-Auer-Systeme Verlag.

Klerman, G. L., Weissman, M. M., Rounsaville, B. J., \& Chevron, E. (1984). Interpersonal psychotherapy of depression. New York: Basic Books.

Lambraki, M., Kilaidakis, S., \& Paritsis, N. (2014). Human Systems Therapy for adolescent cannabis use. In C. Soldatos, P. Ruiz, D. Dikaios, and M. Riba (Eds.), Pluralism in psychiatry: Diversity and convergence (pp. 161-164). Medimond International Proceedings.

Lambraki, M., \& Paritsis, N. (2019). Four-sessions intervention outcome. EFTA conference. Napoli.

Liddle, H. (2010). Multidimensional Family Therapy: A science-based treatment system. Australian and New Zealand Journal of Family Therapy, 31(2), 133-148.

Miller, J. (1978). Living systems. London: Chapman and Hall.

Minuchin, S. (1974). Families and family therapy. Cambridge, Massachusetts: Harvard University Press.

Maturana, H., Lettvin, J., McCouloch, W., \& Pitts, W. (1960). Anatomy and physiology of vision in the frog. J. Gen. Physiology, 43(6), 129-175.

Maturana, H. (1981). Neurophysiology of cognition. In P. Garvin (Ed.), Cognition: A multiple view (pp. 3-23). New York: Spartan Books.

Maturana, H., \& Varela, F. (1984). The tree of knowledge: The biological roots of human understanding. Boston: Shamhala Books.

Paracelsus. (1494-1541). Medieval alchemist.

Paritsis, N. (1985). A model of man as a hierarchical and purposeful intelligent system. In B. Banathy (Ed.), Systems inquiring, Vol. II (pp. 102-107). Seaside, California: Intersystems Publication.

Paritsis, N. (1987). Man as a hierarchical and purposeful intelligent system. Systems Research, 4(3), 169-176.

Paritsis, N. (1989), Towards a general systems therapy of human behaviour. In Ledington R. (ed.), Proceedings of the 33rd Annual meeting of the International Society for the Systems Science, pp. 254-260.

Paritsis, N. (1993). Societal evolution: A process without random variation. World Futures, 37, 173-178. 
Paritsis, N. (1997). Sociocultural systems design based on collective intelligent functions. Cybernetica, XL(4), 297-318.

Paritsis, N. (1999). "The balance of variety with order: A necessity for the developing sustainable systems". Proceedings of the International Conference of the Researsh Committee of Socio-cybernetics, on Problems of complexity and emergence in sustainable systems». May 26-31 1999, Kolimbari, Crete, Greece.

Paritsis, N. (2006). Systemic psychiatry, Vol II. Human systems evolution and therapy. Athens (Gr): BETA Medical Publishers.

Paritsis, N. (2010). Human Systems Therapy. Syst. Res., 26, 1-13.

Paritsis, N., \& Destounis, N. (1982). Conscious and unconscious motivation towards interaction and development. Dynamiche Psychiatrie, 76-77, 227-239.

Paritsis, N., \& Stewart, D. (1979). An interaction theory of motivation and purpose in natural intelligent systems. In R. Ericson (Ed.), Improving the human condition: Quality and stability in social systems (pp. 866-874). California: Society for General Systems Research.

Paritsis, N., \& Stewart, D. (1983). A cybernetic approach to colour perception. London: Gordon and Breach.

Popper, K. (1959). The logic of scientific discovery. New York, NY: Basic Books.

Prigogine, I., \& Stengers, I. (1984). Order out of chaos. London: Fontana Paperbacks.

Rogers, C. R. (1942). Counseling and psychotherapy. Boston: Houghton Mifflin.

Rosenblueth, A., Wiener, N., \& Bigelow, J. (1943). Behavior, purpose and teleology. Phil. Sci., 10(1), 18-24.

Russell, B., \& Whitehead, A. (1910). Principia mathematica. Cambridge: Cambridge University Press.

Selvini Palazzoli, M., Boscolo, L., Ceccin, G., \& Prata, G. (1978). Paradox and caunter-paradox. New York: Iason Aronson.

Stratton, P., Lask, J., Bland, J., Nowotny, E., Evans, C., Singh, R., Janes, E., \& Peppiatt, A. (2014). Detecting therapeutic improvement early in therapy: Validation of the SCORE-15 index of family functioning and change. Journal of Family Therapy, 36(1), 3-19.

Sullivan, H. S. (1953). The interpersonal theory of psychiatry. New York: Norton.

Vedas. (2500 B.C.). Ancient Indian religious writings.

Wiener, N. (1948). Cybernetics: Or control and communication in the animal and the machine. Cambridge, Massachussetts: The MIT Press. 